\title{
Curing behavior and thermal properties of trifunctional epoxy resin cured by 4, 4'-diaminodiphenyl sulfone
}

\author{
J. Cheng*, J. Li, J. Y. Zhang \\ College of Materials Science and Engineering, Beijing University of Chemical Technology, Beijing 100029, China
}

Received 5 April 2009; accepted in revised form 24 May 2009

\begin{abstract}
A novel trifunctional epoxy resin 4-(3, 3-dihydro-7-hydroxy-2, 4, 4-trimethyl-2H-1-benzopyran-2-yl)-1, 3-benzenediol glycidyl (shorted as TMBPBTH-EPOXY) was synthesized in our lab to improve thermal performance. Its curing behavior and performance were studied by using $4,4^{\prime}$-diaminodiphenyl sulfone (DDS) as hardener with the mass ratio of 100:41 of TMBPBTH-EPOXY and DDS. The curing activation energy was investigated by differential scanning calorimetry (DSC) to be $64.0 \mathrm{~kJ} / \mathrm{mol}$ estimated by Kissinger's method and $68.7 \mathrm{~kJ} / \mathrm{mol}$ estimated by Flynn-Wall-Ozawa method respectively. Thermogravimetric analyzer (TGA) was used to investigate the thermal decomposition of cured compounds. It was found that when curing temperature was lower than $180^{\circ} \mathrm{C}$, the thermal decomposition temperature increased with the rise of curing temperature and curing time. On the other hand, when the curing temperature was higher than $180^{\circ} \mathrm{C}$, the thermal decomposition temperature went down instead with the increase of curing time that might be the over-crosslinking of TMBPBTH-EPOXY and DDS hardener. The glass transition temperature $\left(T_{g}\right)$ of cured TMBPBTH-EPOXY/DDS compound determined by dynamic mechanical thermal analysis (DMTA) is $290.1^{\circ} \mathrm{C}$.
\end{abstract}

Keywords: thermosetting resins, trifunctional epoxy resin, curing behavior, glass transition temperature, thermal decomposition temperature

\section{Introduction}

Epoxy resins have been known to possess good mechanical properties and excellent adhesive properties, and thus have been widely used in industry, such as adhesive, coating, laminating, electronic encapsulating materials, and composite applications [1-7]. However, the conventional epoxy resins are inefficient to satisfy the required properties of advanced materials, such as, high thermal resistance [8-10]. It is known that several ways can be taken to enhance the thermal property of epoxy compound. Firstly, the aromatic ring was introduced into epoxy backbone during synthesis, for example, naphthalene ring and biphenyl group were often used to improve the heat resistance of epoxy resin [11-15]. Secondly, multifunctional epoxy resin is a way to enhance heat-resistant prop- erty because of higher curing density [16-18]. Recently, multifunctional epoxy resins attracted extensive interest of researchers and producers, and some multifunctional epoxy resins have been reported and even used in industrial application [19, 20], for example [21-23], novolac epoxy resin, cycloalphatic epoxy resin, tetraglycidyl diamine diphenol methane (TGDDM), triglycidyl ether p-aminophenol (AGF-90) and resorcinol-formaldehyde type epoxy resin (F-76). Some typical structures of multifunctional epoxy resin were showed in Figure 1, which are mainly employed as matrix for high performance fiber-reinforced composites in the aerospace industry and as encapsulant for electronic components.

Thirdly, the properties and performance of cured compounds of epoxy resins are also dependent on 


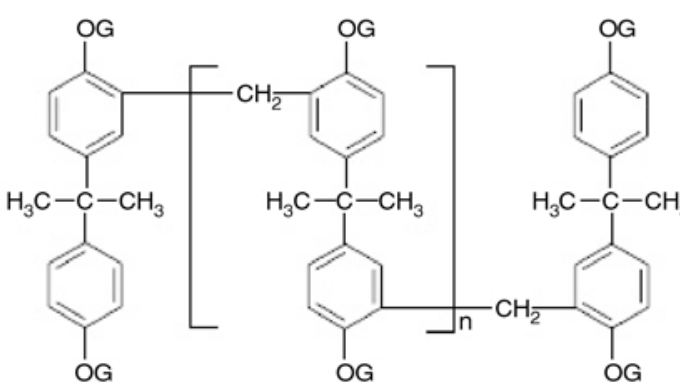<smiles>O=C(O)C1CC2OC2CC1C(=O)O[Na]</smiles>

bisphenol novolac epoxy resin

cycloalphatic epoxy resin (TDE85)<smiles>COc1ccccc1Cc1cccc(Cc2ccccc2[N+](=O)[O-])c1[O+]([O-])O[Na]</smiles>

novolac epoxy resin<smiles>[AlH2]N([AlH2])c1ccc(Cc2ccc(N([Hg])[TlH2])cc2)cc1</smiles>

TGDDM (AG-80)
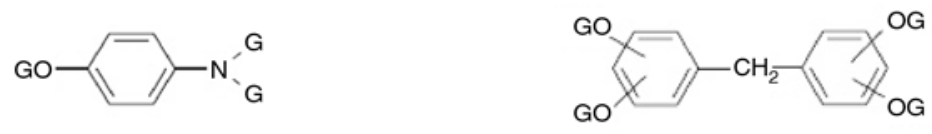

AGF-90

F-76

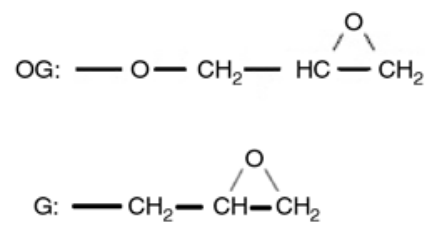

Figure 1. The structures of some typical multifunctional epoxy resins

the type of curing agent, and curing conditions [24]. Among the long list of curing agents, the aromatic primary amines are known to impart high glass transition temperature $\left(T_{g}\right)$ to cured resins, for example, 4, 4'-diaminodiphenyl sulfone (DDS) and $4,4^{\prime}$-diaminodiphenylmethane (DDM). The $T_{g}$ of cured resin with DDS as hardener is higher than DDM because of its sulfone structure.
In this paper, the resin is a new kind of trifunctional resin synthesized in our lab [25] with the structure shown in Figure 2 (structure 2), and DDS is chosen as hardener. The aim of our work is to investigate the curing behavior and thermal stability of the novel TMBPBTH-EPOXY/DDS system by Fourier Transform Infrared Spectroscopy (FTIR), differential scanning calorimetry (DSC), dynamic mechan-

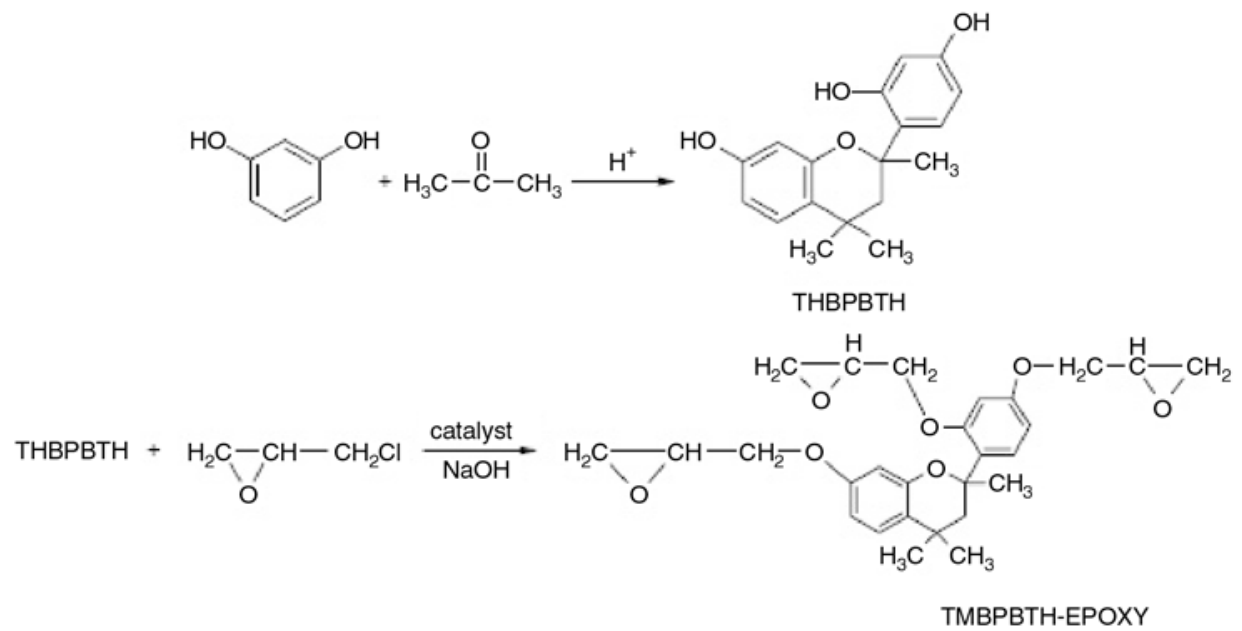

Figure 2. Reaction mechanisms of THВРВTH and TMBРВТН-EPOXY 
ical thermal analysis (DMTA), and thermo-gravimetric analysis (TGA). The FTIR was used to monitor the residual epoxide functional groups during the curing process with the curing temperatures changing from 140 to $220^{\circ} \mathrm{C}$, and curing time lasting from 1 to 6 hours. DSC was used to investigate the curing kinetics of TMBPBTH-EPOXY/DDS system. DMTA and TGA were used to characterize the glass transition temperature and decomposition temperature of cured compounds as a function of cure temperature, respectively.

\section{Materials and methods}

\subsection{Materials}

Epichlorohydrin was supplied by Beijing Chemical Plant. Quaternary ammonium salt was from Tianjin Jinke fine Chemical institute used as phase transition catalyst. $\mathrm{NaOH}$ was analytical reagent supplied by Beijing Chemical Plant. DDS was supplied by Shanghai SSS Reagent Co., Ltd. used as curing agent. 4-(3, 3-dihydro-7-hydroxy-2, 4, 4trimethyl-2H-1-benzopyran-2-yl)-1, 3-benzenediol (THBPBTH) was a trifunctional phenol synthesized by the reaction of resorcinol and acetone [25] and the reaction mechanism was showed in Figure 2 .

\subsection{Synthesis of trifunctional epoxy resin}

TMBPBTH-EPOXY was synthesized by the reaction of described THBPBTH and epichlorohydrin through well-known two-step process with quaternary ammonium salt as catalyst. The THBPBTH and epichlorohydrin react in the four-neck flask equipped with thermometer, vacuum unit, nitrogen tank and peristaltic pump for 1 hour at $100^{\circ} \mathrm{C}$ under nitrogen atmosphere. Then, $\mathrm{NaOH}$ aqueous $(50 \mathrm{wt} \%)$ is added gradually for another 1.5 hour at $65^{\circ} \mathrm{C}$. After reaction the product is dissolved in toluene and washed by deionized water three times. The epoxy resin was obtained after drying under the vacuum. The epoxide equivalent weight (EEW) of TMBPBTH-EPOXY is 161-164 analyzed by hydrocholoride-acetone method. Accordingly, based on the determined EEW value, TMBPBTHEPOXY mixed with DDS at the weight ratio of 100:41.

\subsection{DSC measurements for curing kinetics}

A PerkinElmer Pyrisl differential scanning calorimeter was used to investigate the curing behavior of TMBPBTH-EPOXY/DDS in nitrogen atmosphere. TMBPBTH-EPOXY/DDS mixtures (about $4.0 \mathrm{mg}$ each) were subjected to DSC scans at heating rates of 5, 10, 15, and $20 \mathrm{~K} \cdot \mathrm{min}^{-1}$, respectively, the test specification is from room temperature to $350^{\circ} \mathrm{C}$.

The curing reaction kinetic parameters can be evaluated with a multiple-heating-rate method by determining the exothermic peak temperatures at several heating rates. In practice, two convenient multipleheating-rate methods are generally used. One is the maximum reaction rate method proposed by Kissinger, which is based on the fact that the exothermic peak temperature $\left(T_{p}\right)$ varied with the heating rates. The other is the iso-conversion method proposed by Flynn, Wall, and Ozawa, which is based on the fact that iso-conversion can be reached at different temperatures with various heating rates [26].

Kissinger's approach assumed that the maximum reaction rate occurred at peak temperatures, where $\mathrm{d}^{2} \alpha / \mathrm{d} t^{2}$, it can be expressed by Equation (1):

$\ln \left(\frac{\beta}{T_{p}^{2}}\right)=\ln \left(\frac{A R}{E_{a}}\right)-\frac{E_{a}}{R T_{p}}$

where $\alpha$ is the state of cure, $\beta$ is the linear heating rate $\left[\mathrm{K} \cdot \mathrm{min}^{-1}\right], T_{p}$ is he peak temperature $[\mathrm{K}], A$ is the pre-exponential factor, $E_{a}$ is the activation energy, and $R$ is the universal gas constant ( $R=$ $8.314 \mathrm{~kJ} / \mathrm{mol} \cdot \mathrm{K})$. Therefore, a plot of $\ln \left(\beta / T_{p}^{2}\right)$ versus $1 / T_{p}$ gives the values of $E_{a}$ and $A$.

Flynn-Wall-Ozawa method assumes that the degree of conversation at peak temperatures for different heating rates is constant. It can be expressed by Equation (2):

$$
\log \beta=-\frac{0.4567 E_{a}}{R T}+C
$$

where $C$ is a constant, $T$ is the iso-conversion temperature, and other parameters are the same as described earlier. Plotting $\log \beta$ versus $1 / T$ the activation energy can be obtained from the slope.

\subsection{FTIR measurements for curing reaction}

A Nicolet Nexus 670 spectrometer was used to monitor the variation of epoxide functional groups 
of TMBPBTH-EPOXY/DDS system as the function of curing temperature and curing time during curing process. The sample was made into powder, and mixed with potassium bromide, and then it was made as a thin film at room temperature and the resolution was $4 \mathrm{~cm}^{-1}$. The potassium bromide was used as the background.

\subsection{TGA measurements for thermal decomposition temperature}

A TG209C thermo-gravimetric analyzer produced by Netzsch Company was used to determine the thermal decomposition temperatures of cured materials in nitrogen atmosphere at heating rate of $20 \mathrm{~K} \cdot \mathrm{min}^{-1}$. The onsets are at about $5 \%$ weight loss, the test specification is from room temperature to $600^{\circ} \mathrm{C}$

\section{6. $T_{g}$ analyzed by DMTA}

An American Rheometric Scientific DMTA V dynamic mechanical thermal analysis was used to determine the $T_{g}$ of cured TMBPBTH-EPOXY sample. The bending method was used with a frequency of $1 \mathrm{~Hz}$ and a strain level of $0.04 \%$ in the temperature range from 20 to $350^{\circ} \mathrm{C}$. The heating rate was $5 \mathrm{~K} \cdot \mathrm{min}^{-1}$. The testing was performed by using rectangular bars of approximate $50 \times 8 \times$ $2 \mathrm{~mm}^{3}$. The exact dimensions of each specimen were measured before the scanning.

It can determine continuously in wide temperature or frequency range, and get the relationship of rigidity and damping with temperature, frequency or time in a short time. At the aspect of determining material's glass transition and secondary transition, it has better sensitivity than DTA and DSC.

\section{Results and discussion}

\subsection{Curing kinetics}

In Figure 3, the heat flow is plotted as a function of the temperature for four different heating rates. It is seen that the exothermic reaction proceed in a wide temperature range, and the maximum rate temperatures of the curing reaction increased with increasing heating rate. The values of activation energy $E_{a}$ and $A$ of TMBPBTH-EPOXY/DDS systems can be calculated from the slopes of the linear lines in Figure 4 , and all the exothermic peak temperatures

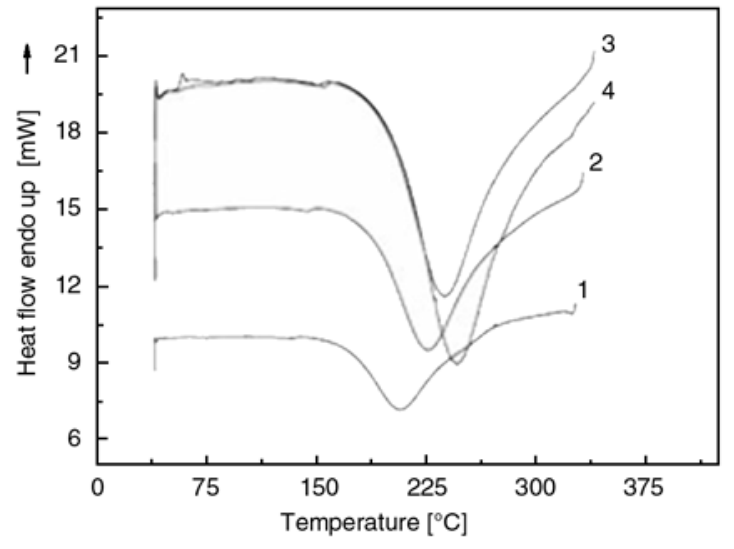

Figure 3. DSC curves of TMBPBTH-EPOXY/DDS. Heating rate: $1-5 \mathrm{~K} \cdot \mathrm{min}^{-1} ; 2-10 \mathrm{~K} \cdot \mathrm{min}^{-1}$; 3 - $15 \mathrm{~K} \cdot \mathrm{min}^{-1} ; 4-20 \mathrm{~K} \cdot \mathrm{min}^{-1}$.
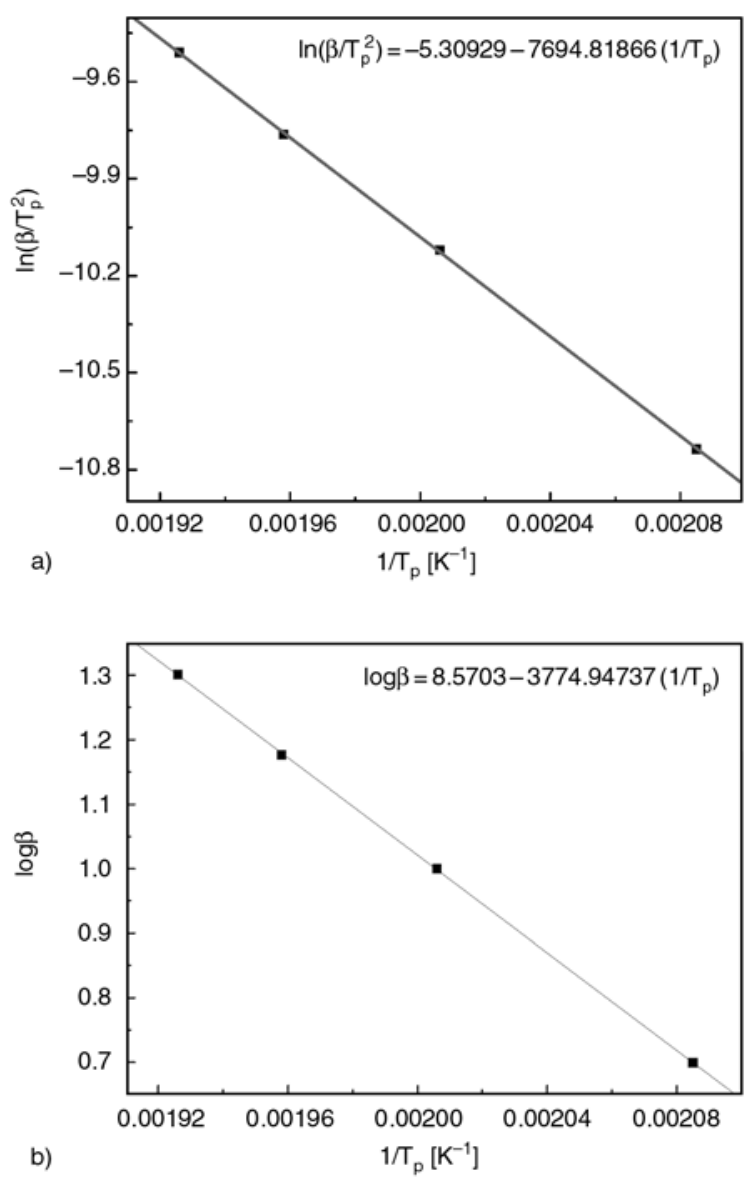

Figure 4. Kinetics analysis of TMBPBTH-EPOXY/DDS curing system TMBPBTH-EPOXY/DDS: a) $\ln \left(\beta / T_{p}^{2}\right)-1 / T_{p}$, b) $\log \beta-1 / T_{p}$

$\left(T_{p}\right)$ of the DSC curves at different heating rates are listed in Table 1, and the curing kinetic parameters determined by the Kissinger and Flynn-WallOzawa methods are also summarized in Table 1. According to the Equation (1), it was calculated that $E_{a}$ of TMBPBTH-EPOXY/DDS curing system 
Table 1. Kinetics data of TMBPBTH-EPOXY/DDS

\begin{tabular}{|l|r|r|r|r|}
\hline \multirow{2}{*}{} & \multicolumn{4}{|c|}{$\boldsymbol{\beta}\left[\mathbf{K} \cdot \mathbf{m i n}^{-1}\right]$} \\
\cline { 2 - 5 } & \multicolumn{1}{|c|}{$\mathbf{5}$} & \multicolumn{1}{|c|}{$\mathbf{1 0}$} & \multicolumn{1}{c|}{$\mathbf{1 5}$} & \multicolumn{1}{c|}{$\mathbf{2 0}$} \\
\hline$T_{p}[\mathrm{~K}]$ & 479.532 & 498.526 & 510.674 & 519.118 \\
\hline $1 / T_{p}\left[\times 10^{-3} / \mathrm{K}\right]$ & 2.085 & 2.006 & 1.958 & 1.926 \\
\hline $\ln \beta$ & 1.609 & 2.303 & 2.708 & 2.996 \\
\hline $\log \beta$ & 0.699 & 1.000 & 1.176 & 1.301 \\
\hline $\ln \left(\beta / T_{p}^{2}\right)$ & -10.736 & -10.121 & -9.763 & -9.509 \\
\hline
\end{tabular}

is $64.0 \mathrm{~kJ} / \mathrm{mol}$, and $A$ is $38.05 \mathrm{~s}^{-1}$. According to Equation (2), it was calculated that $E_{a}$ of TMBPBTH-EPOXY/DDS curing system is $68.7 \mathrm{~kJ} / \mathrm{mol}$.

Because of thermal hysteresis, curing temperatures were different according to different heating rates. However, materials are often cured at constant temperature or stepped heating state actually, because at that time the heating rate is $0 \mathrm{~K} / \mathrm{min}$. Therefore, method of extrapolation of $T-\beta$ is used to get the isothermal curing temperature of curing system, and then determine the best curing process. The data is showed in Table 2, and Figure 5 is $T-\beta$ analysis, whereas, $T_{i}, T_{p}$ and $T_{0}$ means onset temperature, peak temperature and end temperature respectively.

When the $T-\beta$ analysis in Figure 5 are extrapolated until $\beta$ equals to $0, T_{i}, T_{p}$ and $T_{0}$ of isothermal curing would be gained. $T_{i}, T_{p}$ and $T_{0}$ of TMBPBTHEPOXY/DDS system is $136.7,196.1$ and $241.1^{\circ} \mathrm{C}$

Table 2. DSC data of TMBPBTH-EPOXY/DDS curing system

\begin{tabular}{|c|c|c|c|c|}
\hline \multirow{2}{*}{} & \multicolumn{4}{|c|}{$\boldsymbol{\beta}\left[\mathbf{K} \cdot \mathbf{m i n}^{-1}\right]$} \\
\cline { 2 - 5 } & $\mathbf{5}$ & $\mathbf{1 0}$ & $\mathbf{1 5}$ & $\mathbf{2 0}$ \\
\hline$T_{i}[\mathrm{~K}]$ & 415.900 & 425.520 & 432.515 & 437.551 \\
\hline$T_{p}[\mathrm{~K}]$ & 479.532 & 498.526 & 510.674 & 519.118 \\
\hline$T_{0}[\mathrm{~K}]$ & 534.391 & 578.552 & 603.912 & 618.820 \\
\hline
\end{tabular}

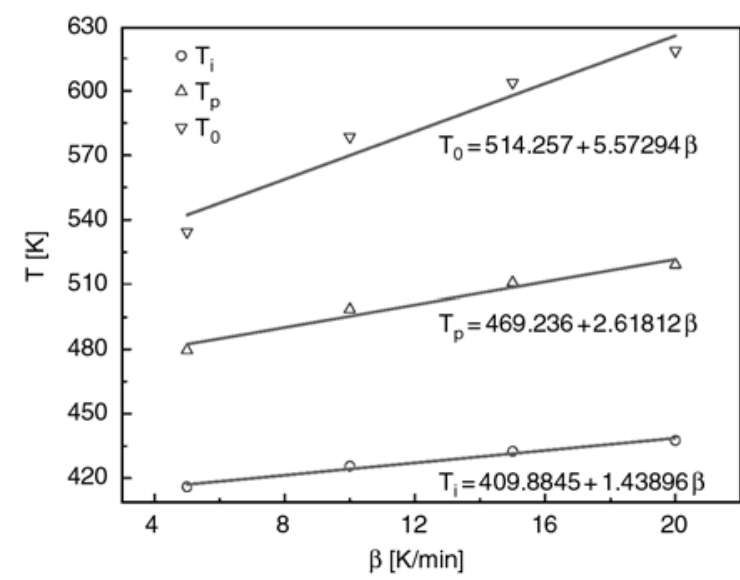

Figure 5. T- $\beta$ analysis of TMBPBTH-EPOXY/DDS curing system
Table 3. Curing processes of TMBPBTH-EPOXY/DDS curing system

\begin{tabular}{|c|c|}
\hline Curing system & Curing process $\left[{ }^{\circ} \mathbf{C} / \mathbf{h}\right.$ ] \\
\hline TMBPBTH-EPOXY/DDS & $140 / 2+200 / 2+220 / 4$ \\
\hline
\end{tabular}

respectively. The curing system was heated from 136.7 to $196.1^{\circ} \mathrm{C}$ gradually, and then cured at $196.1^{\circ} \mathrm{C}$ isothermally for 2 hours; at last, it was heated to $241.1^{\circ} \mathrm{C}$ and remained for a certain time. Because all of these, the best curing process was determined, which is shown in Table 3.

\subsection{FTIR study of curing reaction}

The epoxide functional group is the characteristic group in the epoxy resin, and epoxide rings will open under the attack of amine molecule during the curing reaction of epoxy resins by amine curing agent, which will decrease the content of epoxide groups drastically. The curing mechanism of TMBPBTH-EPOXY and DDS is shown in Figure 6. Thus, FTIR is effective method to investigate the curing behavior of epoxy resin by determining the change of functional groups before and after curing reactions of epoxy resin. The experimental results were shown in Figure 7 and Table 4.

Figure 7 presents the FTIR spectra of the cured compound of TMBPBTH-EPOXY/DDS system. The assignments of the absorption features are as follows: about $1595,1503 \mathrm{~cm}^{-1}$ to phenyl group, $1257 \mathrm{~cm}^{-1}$ to phenylate, $1104,1032 \mathrm{~cm}^{-1}$ to fatty ether, $910 \mathrm{~cm}^{-1}$ to epoxide group and $827 \mathrm{~cm}^{-1}$ to the out-of-plane deformation of the aromatic $\mathrm{CH}$. It can be seen from Figure 7 that after cured at $140^{\circ} \mathrm{C}$ for 1 hour, the relative absorption intensity of epoxide group still remained obviously, and even if the curing time was increased up to 6 hours the absorption peak at $910 \mathrm{~cm}^{-1}$ decreased a little (see Figure $7 \mathrm{a}$ and $7 \mathrm{~b}$ ). When the curing temperature was up to $160^{\circ} \mathrm{C}$, the absorption intensity at $910 \mathrm{~cm}^{-1}$ weakened compared to that cured at $140^{\circ} \mathrm{C}$, and 6 hours curing time had a little influence on the opening reaction of epoxide ring compared with 1 hour cured (see Figure $7 \mathrm{c}$ and $7 \mathrm{~d}$ ). When the curing temperature was up to $180^{\circ} \mathrm{C}$, the absorption peak at $910 \mathrm{~cm}^{-1}$ became not clear, especially for the curing time of 6 hours (see Figure 7e and 7f). Furthermore, when the curing temperature rose to $220^{\circ} \mathrm{C}$, after cured for 2 hours, the 


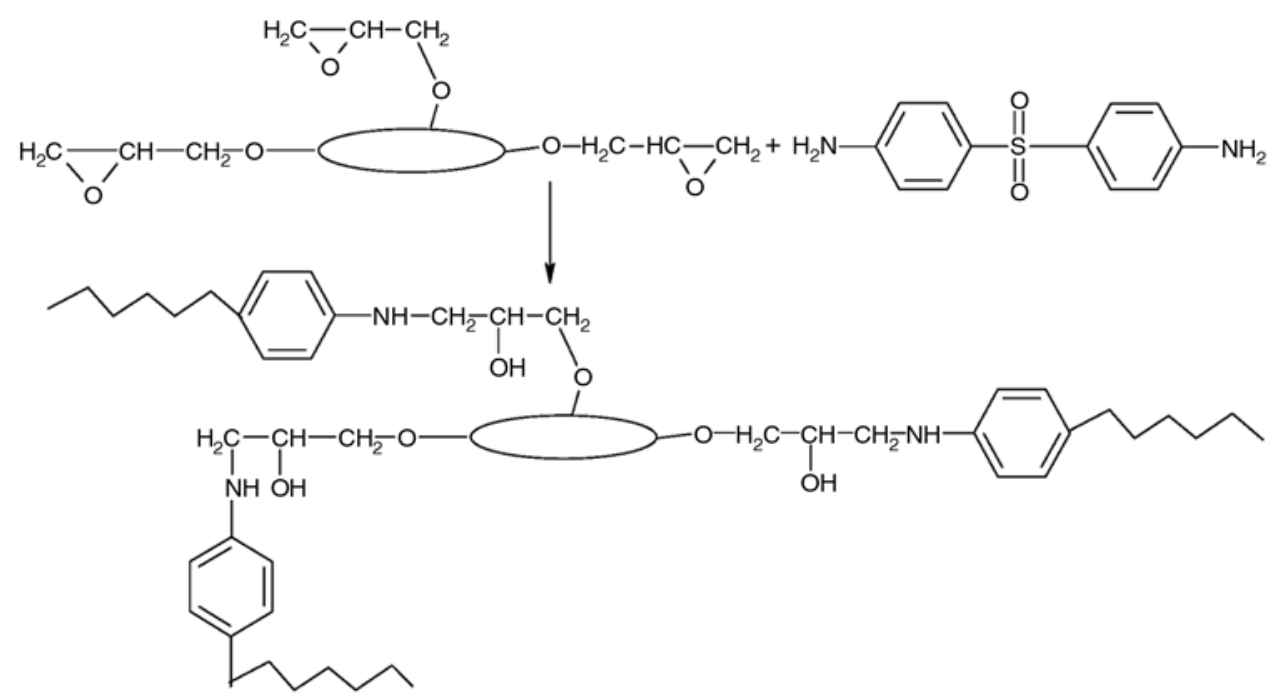

Figure 6. the curing reaction mechanism of THTMBPB-EPOXY with DDS

Table 4. The epoxide groups index of TMBPBTH-EPOXY/DDS system

\begin{tabular}{|c|c|c|c|c|}
\hline \multirow{2}{*}{$\begin{array}{c}\text { Curing time } \\
{[\mathbf{h}]}\end{array}$} & \multicolumn{3}{|c|}{$\mathbf{T}\left[{ }^{\circ} \mathbf{C}\right]$} \\
\cline { 2 - 5 } & $\mathbf{1 4 0}$ & $\mathbf{1 6 0}$ & $\mathbf{1 8 0}$ & $\mathbf{2 2 0}$ \\
\hline 1 & $0.0370 \pm 0.0008$ & $0.0199 \pm 0.0005$ & $0.0144 \pm 0.0006$ & $0.0083 \pm 0.0004$ \\
\hline 6 & $0.0191 \pm 0.0006$ & $0.0163 \pm 0.0011$ & $0.0142 \pm 0.0009$ & $0.0078 \pm 0.0009$ \\
\hline
\end{tabular}

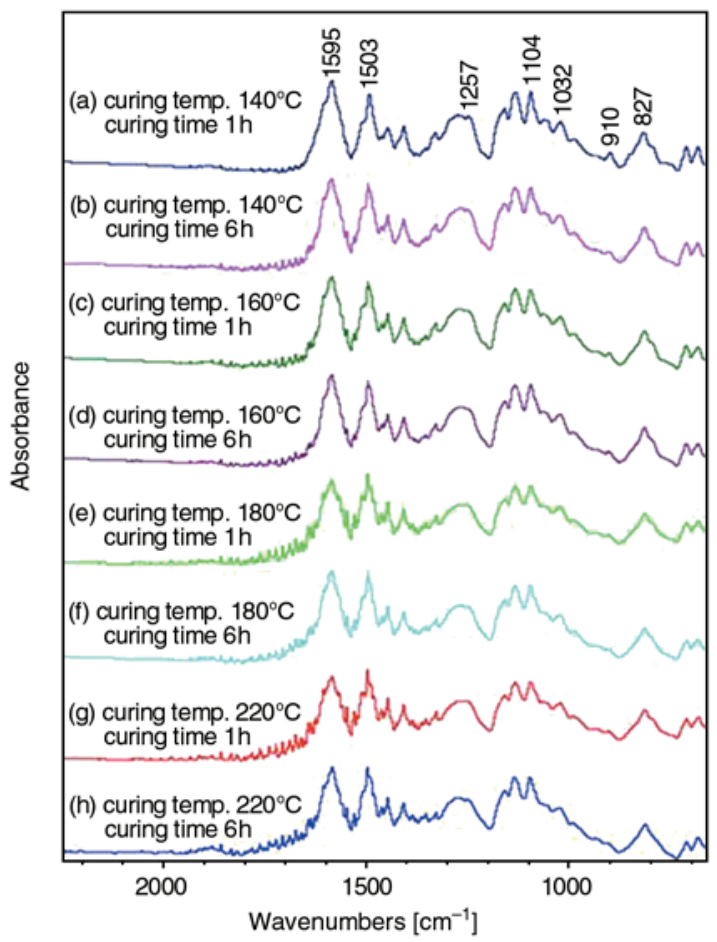

Figure 7. FTIR spectra of the TMBPBTH-EPOXY/DDS system cured at different temperature

absorption intensity of residual epoxide groups at $910 \mathrm{~cm}^{-1}$ was tiny, when the curing time reached 6 hours, the absorption peak at $910 \mathrm{~cm}^{-1}$ disappeared (see Figure $7 \mathrm{~g}$ and $7 \mathrm{~h}$ ).
The FTIR analysis results elucidated that curing temperature impacted on the curing reaction more obvious than curing time. In order to show the changes of residual epoxide group with the curing temperature and curing time, the epoxide group index was calculated by using absorption intensity of phenyl groups as internal standard and the calculation equation as follows:

Epoxide group index $=$ $\frac{\text { epoxide group's peak area }}{\text { phenyl group's peak area }}=\frac{A_{923-887}}{A_{1680-1548}}$

The area of epoxide group in FTIR spectra is from 887 to $923 \mathrm{~cm}^{-1}$, the area of phenyl group in FTIR spectra is from 1548 to $1680 \mathrm{~cm}^{-1}$.

The calculated results were shown in Table 4.

\subsection{Thermal decomposition temperature of TMBPBTH-EPOXY/DDS system}

The thermal decomposition temperatures of cured compounds are different depending on the curing conditions of different curing temperature and curing time. TGA was used to determine thermal decomposition temperatures of TMBPBTHEPOXY/DDS curing system at curing temperatures of $140,160,180$ and $220^{\circ} \mathrm{C}$ for curing time of 1,2 , 


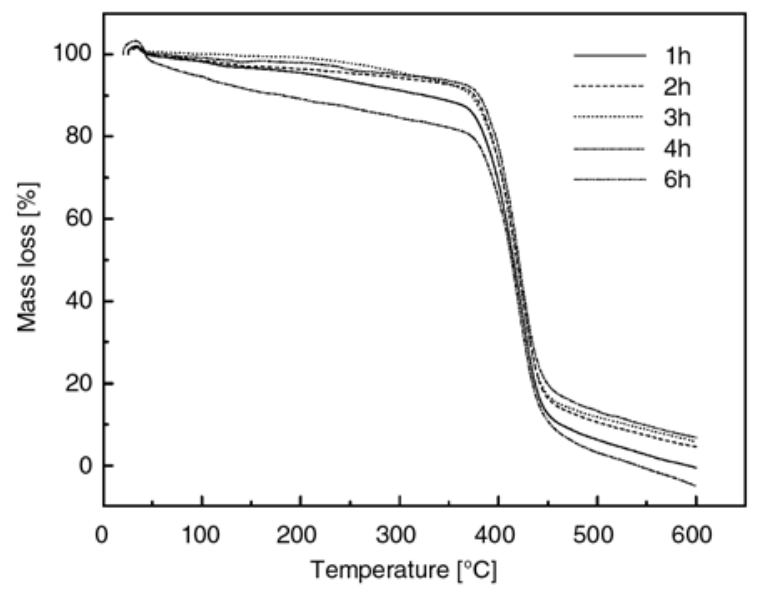

Figure 8. TGA curves of TMBPBTH-EPOXY/DDS curing system cured at $140^{\circ} \mathrm{C}$. Curing time: $1,2,3$, $4,6 \mathrm{~h}$.

3,4 and $6 \mathrm{~h}$ respectively. The measurement results of sample cured at $140^{\circ} \mathrm{C}$ were plotted in Figure 8 and all samples results with $T_{0}, T_{i}$ and $T_{e}$ data were listed in Table 5, whereas, $T_{0}, T_{i}$ and $T_{e}$ are onset temperature, middle temperature and offset temperature of thermal decomposition.

It indicated in Table 5 that thermal decomposition temperature increased slightly with the increasing of curing time from 1 to 6 hours at the same curing temperature of 140 and $160^{\circ} \mathrm{C}$. This change was attributed to the increase of density of cross linking caused by curing for longer time, which resulted in more perfectly crosslinked network.

Table 5. Thermal decomposition temperatures of TMBPBTH-EPOXY/DDS

\begin{tabular}{|c|c|c|c|c|}
\hline $\begin{array}{c}\text { Curing temperature } \\
{\left[{ }^{\circ} \mathrm{C}\right]}\end{array}$ & $\begin{array}{c}\text { Curing time } \\
{[\mathrm{h}]}\end{array}$ & $T_{0}\left[{ }^{\circ} \mathrm{C}\right]$ & $T_{i}\left[{ }^{\circ} \mathrm{C}\right]$ & $\boldsymbol{T}_{e}\left[{ }^{\circ} \mathbf{C}\right]$ \\
\hline \multirow{5}{*}{140} & 1 & 389.0 & 424.6 & 443.4 \\
\hline & 2 & 389.3 & 424.2 & 443.2 \\
\hline & 3 & 391.5 & 422.3 & 441.0 \\
\hline & 4 & 393.0 & 420.3 & 440.9 \\
\hline & 6 & 394.0 & 421.2 & 441.9 \\
\hline \multirow{5}{*}{160} & 1 & 391.1 & 424.8 & 443.7 \\
\hline & 2 & 392.1 & 424.6 & 443.3 \\
\hline & 3 & 394.9 & 426.3 & 443.9 \\
\hline & 4 & 394.6 & 425.5 & 443.8 \\
\hline & 6 & 395.3 & 426.1 & 442.7 \\
\hline \multirow{5}{*}{180} & 1 & 394.2 & 425.5 & 443.1 \\
\hline & 2 & 389.1 & 424.0 & 441.7 \\
\hline & 3 & 387.3 & 422.3 & 441.6 \\
\hline & 4 & 388.8 & 423.4 & 442.6 \\
\hline & 6 & 386.3 & 420.8 & 440.7 \\
\hline \multirow{5}{*}{220} & 1 & 396.4 & 426.6 & 442.9 \\
\hline & 2 & 392.3 & 425.4 & 444.4 \\
\hline & 3 & 390.8 & 424.3 & 441.4 \\
\hline & 4 & 390.7 & 424.3 & 443.5 \\
\hline & 6 & 390.6 & 424.5 & 443.1 \\
\hline
\end{tabular}

However, thermal decomposition temperatures decreased slightly with the increasing of curing time from 1 to 6 hours at 180 and $220^{\circ} \mathrm{C}$. This change can be explained to excess cross linking of epoxy resin and hardener, or overcured which gave inner stress and then deficiency appeared. These deficiencies made the thermal decomposition temperature declined. With the increase of curing time the deficiencies became more serious and decomposition temperature decreased gradually.

However, thermal decomposition temperatures cured at 180 and $220^{\circ} \mathrm{C}$ are higher than cured at 140 and $160^{\circ} \mathrm{C}$, it means high curing temperature is more helpful for curing reaction, and the increasing of curing time has advantageous effect on curing reaction when the curing temperature is lower than $160^{\circ} \mathrm{C}$. This is coincident with the analysis of FTIR.

\subsection{Glass transition temperature of epoxy resin network}

$T_{g}$ of an epoxy resin network is the reflection of the structure for different epoxy resins when the curing reaction is complete.

DMTA is used to determine dynamic mechanical property of materials in a certain temperature range. Here, TMBPBTH-EPOXY/DDS curing system was studied by DMTA at fixed frequency. At fixed frequency, the value of $\tan \delta$ reaches maximum at glass transition temperature, so the value of $T_{g}$ can determined by the curve of $\tan \delta$.

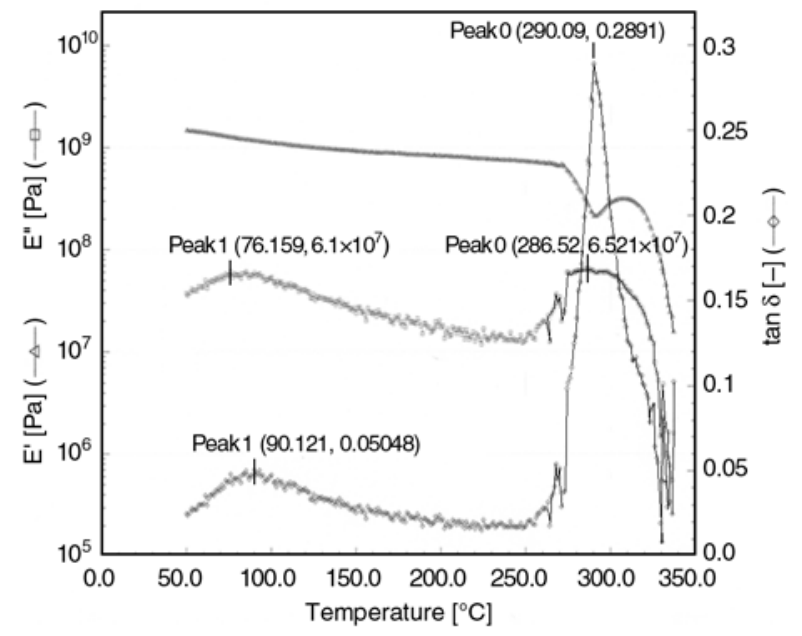

Figure 9. DMTA curve of TMBPBTH-EPOXY/DDS curing system 
Figure 9 is DMTA spectra of TMBPBTH-EPOXY/ DDS. $T_{g}$ of TMBPBTH-EPOXY/DDS curing system is about $290.1^{\circ} \mathrm{C}$.

\section{Conclusions}

DSC studies show that the curing activation energies of TMBPBTH-EPOXY/DDS systems are $64.0 \mathrm{~kJ} / \mathrm{mol}$ estimated by Kissinger's approach and $68.7 \mathrm{~kJ} / \mathrm{mol}$ estimated by Flynn-Wall-Ozawa method respectively. FTIR studies indicates that state of cure of TMBPBTH-EPOXY/DDS curing system is mainly dependent on curing temperature and it is increased with increasing temperature, however, it changed a little with increasing curing time at the same curing temperature. TGA studies presents that thermal decomposition temperature increased with increasing curing temperature and time, but it is declined at 180 and $220^{\circ} \mathrm{C}$ for more than $1 \mathrm{~h}$ curing time because of overcuring. The DMTA studies elucidated that $T_{g}$ of TMBPBTHEPOXY/DDS is $290.1^{\circ} \mathrm{C}$.

\section{References}

[1] Gu J., Narang S. C., Pearce E. M.: Curing of epoxy resins with diphenyliodonium salts as thermal initiators. Journal of Applied Polymer Science, 30, 29973007 (1985). DOI: 10.1002/app.1985.070300722

[2] Kaji M., Nakahara K., Endo T.: Synthesis of a bifunctional epoxy monomer containing biphenyl moiety and properties of its cured polymer with phenol novolac. Journal of Applied Polymer Science, 74, 690-698 (1999).

DOI: 10.1002/(SICI)1097-4628(19991017)74:3<690:: AID-APP23>3.0.CO;2-X

[3] Morgan R. J., Mones E. T., Steele W. J.: Tensile deformation and failure processes of amine-cured epoxies. Polymer, 23, 295-305 (1982). DOI: $10.1016 / 0032-3861(82) 90320-2$

[4] Lee J-Y., Shim M-J., Kim S-W.: Autocatalytic cure kinetics of natural zeolite filled epoxy composites. Materials Chemistry and Physics, 48, 36-40 (1997). DOI: 10.1016/S0254-0584(97)80073-9

[5] Lee J. Y., Shim M. J., Kim S. W.: Thermal decomposition kinetics of an epoxy resin with rubber-modified curing agent. Journal of Applied Polymer Science, 81, 479-485 (2001). DOI: $\underline{10.1002 / a p p .1460}$

[6] Lee H., Neville K.: Handbook of epoxy resins. McGraw-Hill, New York (1967).

[7] May C. A., Tanaka Y.: Epoxy resins chemistry and technology. Marcel Decker, New York (1973).
[8] Shieh J-Y., Wang C-S.: Synthesis and properties of novel phosphorus-containing hardener for epoxy resins. Journal of Applied Polymer Science, 78, 1636-1644 (2000).

DOI: 10.1002/1097-4628(20001128)78:9<1636::AIDAPP90>3.0.CO;2-G

[9] Iji M., Kiuchi Y.: Flame-retardant epoxy resin compounds containing novolac derivatives with aromatic compounds. Polymers for Advanced Technologies, 12, 393-406 (2001).

DOI: $10.1002 /$ pat.66

[10] Wang C. S., Lin C. H.: Synthesis and properties of phosphorus containing advanced epoxy resins. Journal of Applied Polymer Science, 75, 429-436 (2000).

DOI: 10.1002/(SICI) 1097-4628(20000118)75:3<429:: AID-APP13>3.0.CO;2-U

[11] Wang C-S., Lee M-C.: Synthesis and modification of a naphthalene-containing trifunctional epoxy resin for electronic applications. Journal of Applied Polymer Science, 70, 1907-1921 (1998).

DOI: $10.1002 /($ SICI $) 1097-4628(19981205) 70: 10$ $\leq 1907::$ AID-APP5 $>3.0 . C O ; 2-Y$

[12] Wang C-S., Lee M-C.: Synthesis, characterization, and properties of multifunctional naphthalene-containing epoxy resins cured with cyanate ester. Journal of Applied Polymer Science, 73, 1611-1622 (1999).

DOI: 10.1002/(SICI)1097-4628(19990829)73:9 $\leq 1611:$ AID-APP2>3.0.CO;2-8

[13] Kaji M., Endo T.: Synthesis of a novel epoxy resin containing naphthalene moiety and properties of its cured polymer with phenol novolac. Journal of Polymer Science Part A: Polymer Chemistry, 37, 3063 3069(1999).

DOI: $10.1002 /($ SICI $) 1099-0518(19990815) 37: 16$ $\leq 3063::$ AID-POLA3>3.0.CO;2-H

[14] Cai Z-Q., Sun J., Zhou Q., Xu J.: Synthesis and characterization of a novel liquid-crystalline epoxy resin combining biphenyl and aromatic ester-type mesogenic units. Journal of Polymer Science Part A: Polymer Chemistry, 45, 727-735(2007).

DOI: $10.1002 /$ pola.21821

[15] Han S., Yoon H. G., Suh K. S., Kim W. G., Moon T. J.: Cure kinetics of biphenyl epoxy-phenol novolac resin system using triphenylphosphine as catalyst. Journal of Polymer Science Part A: Polymer Chemistry, 37, 713-720 (1999).

DOI: 10.1002/(SICI)1099-0518(19990315)37:6<713:: AID-POLA6>3.0.CO;2-I

[16] Carrasco F., Pagès P., Lacorte T., Briceńo K.: Fourier transform IR and differential scanning calorimetry study of curing of trifunctional amino-epoxy resin. Journal of Applied Polymer Science, 98, 1524-1535 (2005). DOI: $10.1002 / a p p .21978$

[17] Mustat'a F., Bicu I.: Multifunctional epoxy resins: Synthesis and characterization. Journal of Applied Polymer Science, 77, 2430-2436 (2000). DOI: $10.1002 / 1097-4628(20000912) 77: 11<2430:$ : AID- APP11>3.0.CO;2-P 
[18] Becker O., Cheng Y-B., Rusell J. V., Simon G. P.: Layered silicate nanocomposites based on various high-functionality epoxy resins: The influence of cure temperature on morphology. Mechanical properties, and free volume. Macromolecules, 36, 1616-1625 (2003).

DOI: $10.1021 / \mathrm{ma} 0213448$

[19] Ochi M., Shimizu Y., Nakanishi Y., Murata Y.: Effect of the network structure on thermal and mechanical properties of mesogenic epoxy resin cured with aromatic amine. Journal of Polymer Science Part B: Polymer Physics, 35, 397-405 (1997).

DOI: 10.1002/(SICI)1099-0488(19970130)35:2<397:: AID-POLB15>3.0.CO;2-D

[20] Wang C-S., Lee M-C.: Synthesis and properties of epoxy resins containing 2-(6-oxid- $6 H$-dibenz(c,e) $(1,2)$ oxaphosphorin-6-yl) 1,4-benzenediol (II). Polymer, 41, 3631-3638 (2000).

DOI: $10.1016 / \mathrm{S} 0032-3861(99) 00541-8$

[21] Atta A. M., Shaker N. O., Nasser N. E.: Synthesis of bisphenol A novolac epoxy resins for coating applications. Journal of Applied Polymer Science, 107, 347354 (2008)

DOI: $10.1002 / \mathrm{app} .26981$
[22] Qian Z., Chen X., Xu J., Guo B.: Chain extension of PA1010 by reactive extrusion by diepoxide 711 and diepoxide TDE85 as chain extenders. Journal of Applied Polymer Science, 94, 2347-2355 (2004). DOI: 10.1002/app.21043

[23] Park S-J., Jin F-L., Lee J-R.: Thermal and mechanical properties of tetrafunctional epoxy resin toughened with epoxidized soybean oil. Materials Science and Engineering: A, 374, 109-114 (2004)

DOI: $10.1016 /$ j.msea.2004.01.002

[24] Jain R., Kukreja P., Narula A. K., Chaudhary V.: Studies of the curing kinetics and thermal stability of epoxy resins using a mixture of amines and anhydrides. Journal of Applied Polymer Science, 100, 3919-3925 (2006).

DOI: $10.1002 / a p p .22769$

[25] Jue C., Jing C., Junying Z., Wantai Y.: Preparation process of polyalkyl hydroxyl benzodihydro pyran derivative. Chinese Patent, 200610113693, China (2008).

[26] Liu Y., Du Z., Zhang C., Li C., Li H.: Curing behavior and thermal properties of multifunctional epoxy resin with methylhexahydrophthalic anhydride. Journal of Applied Polymer Science, 103, 2041-2048 (2007). DOI: 10.1002/app.25291 